NASA/TM-2008-215223

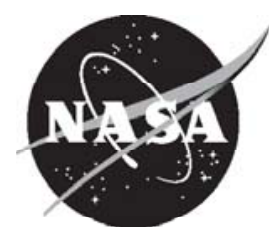

\title{
Misalignment in Gas Foil Journal Bearings: An Experimental Study
}

Samuel A. Howard

Glenn Research Center, Cleveland, Ohio 


\section{NASA STI Program . . . in Profile}

Since its founding, NASA has been dedicated to the advancement of aeronautics and space science. The NASA Scientific and Technical Information (STI) program plays a key part in helping NASA maintain this important role.

The NASA STI Program operates under the auspices of the Agency Chief Information Officer. It collects, organizes, provides for archiving, and disseminates NASA's STI. The NASA STI program provides access to the NASA Aeronautics and Space Database and its public interface, the NASA Technical Reports Server, thus providing one of the largest collections of aeronautical and space science STI in the world. Results are published in both non-NASA channels and by NASA in the NASA STI Report Series, which includes the following report types:

- TECHNICAL PUBLICATION. Reports of completed research or a major significant phase of research that present the results of NASA programs and include extensive data or theoretical analysis. Includes compilations of significant scientific and technical data and information deemed to be of continuing reference value. NASA counterpart of peer-reviewed formal professional papers but has less stringent limitations on manuscript length and extent of graphic presentations.

- TECHNICAL MEMORANDUM. Scientific and technical findings that are preliminary or of specialized interest, e.g., quick release reports, working papers, and bibliographies that contain minimal annotation. Does not contain extensive analysis.

- CONTRACTOR REPORT. Scientific and technical findings by NASA-sponsored contractors and grantees.

- CONFERENCE PUBLICATION. Collected papers from scientific and technical conferences, symposia, seminars, or other meetings sponsored or cosponsored by NASA.

- SPECIAL PUBLICATION. Scientific, technical, or historical information from NASA programs, projects, and missions, often concerned with subjects having substantial public interest.

- TECHNICAL TRANSLATION. Englishlanguage translations of foreign scientific and technical material pertinent to NASA's mission.

Specialized services also include creating custom thesauri, building customized databases, organizing and publishing research results.

For more information about the NASA STI program, see the following:

- Access the NASA STI program home page at http://www.sti.nasa.gov

- E-mail your question via the Internet to help@ sti.nasa.gov

- Fax your question to the NASA STI Help Desk at 301-621-0134

- Telephone the NASA STI Help Desk at 301-621-0390

- Write to: NASA Center for AeroSpace Information (CASI) 7115 Standard Drive Hanover, MD 21076-1320 
NASA/TM-2008-215223

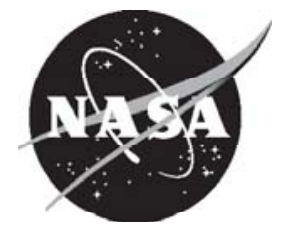

\section{Misalignment in Gas Foil Journal Bearings: An Experimental Study}

Samuel A. Howard

Glenn Research Center, Cleveland, Ohio

Prepared for the

Turbo Expo 2008 Gas Turbine Technical Congress and Exposition sponsored by the American Society of Mechanical Engineers

Berlin, Germany, June 9-13, 2008

National Aeronautics and

Space Administration

Glenn Research Center

Cleveland, Ohio 44135 


\section{Acknowledgments}

The author wishes to acknowledge the support of NASA's Fundamental Aeronautics Program Office, Subsonic Rotary Wing Project.

This report is a preprint of a paper intended for presentation at a conference.

Because changes may be made before formal publication, this preprint is made available with the understanding that it will not be cited or reproduced without the permission of the author.

This work was sponsored by the Fundamental Aeronautics Program at the NASA Glenn Research Center.

Level of Review: This material has been technically reviewed by technical management.

Available from

NASA Center for Aerospace Information 7115 Standard Drive

Hanover, MD 21076-1320
National Technical Information Service 5285 Port Royal Road Springfield, VA 22161 


\title{
Misalignment in Gas Foil Journal Bearings: An Experimental Study
}

\author{
Samuel A. Howard \\ National Aeronautics and Space Administration \\ Glenn Research Center \\ Cleveland, Ohio 44135
}

\begin{abstract}
As gas foil journal bearings become more prevalent in production machines, such as small gas turbine propulsion systems and microturbines, system-level performance issues must be identified and quantified in order to provide for successful design practices. Several examples of system-level design parameters that are not fully understood in foil bearing systems are thermal management schemes, alignment requirements, balance requirements, thrust load balancing, and others. In order to address some of these deficiencies and begin to develop guidelines, this paper presents a preliminary experimental investigation of the misalignment tolerance of gas foil journal bearing systems. Using a notional gas foil bearing supported rotor and a laser-based shaft alignment system, increasing levels of misalignment are imparted to the bearing supports while monitoring temperature at the bearing edges. The amount of misalignment that induces bearing failure is identified and compared to other conventional bearing types such as cylindrical roller bearings and angular contact ball bearings. Additionally, the dynamic response of the rotor indicates that the gas foil bearing force coefficients may be affected by misalignment.
\end{abstract}

\section{Introduction}

Gas foil bearings (GFB) are currently used in several commercial applications, both terrestrial and aerospace. Aircraft Air Cycle Machines (ACMs) and ground-based microturbines have demonstrated histories of successful long-term operation using GFBs (ref. 1). Industrial blowers and compressors are becoming more common as well. Small aircraft propulsion engines, helicopter gas turbines, and highspeed electric motors are potential future applications.

In addition to the industrial and aeronautics applications already mentioned, of particular interest to NASA is the potential to use gas foil bearings in space nuclear power generation. One potential source of electrical power of sufficient magnitude and duration for space power is a nuclear fission based system. The system architecture would consist of a nuclear reactor heat source with the resulting thermal energy converted to electrical energy through a dynamic power conversion and heat rejection system.

A Closed Brayton Cycle (CBC), with an inert gas heated by the reactor driving a gas foil bearing turboalternator, is a potential power conversion scheme. The $\mathrm{CBC}$ for space power and propulsion is described in more detail in the literature (ref. 2).

Regardless of the application, as gas foil bearings are considered for more turbomachinery applications, a better understanding of their system level characteristics is needed for successful design and integration into mainstream machinery. The system level characteristics not yet fully understood include thermal management schemes, alignment requirements, balance requirements, thrust load balancing, and others. This paper presents results of an experimental effort to characterize gas foil bearing misalignment capabilities in the context of how precisely gas foil bearing machinery would need to be manufactured.

\section{Technology Background}

GFBs (fig. 1) consist of an outer sleeve lined with a series of nickel-based superalloy sheet metal foils. The innermost sheet metal foil, or top foil, is smooth and constitutes the bearing inner surface against which the rotating shaft operates. The top foil is supported by a compliant structure, often made 


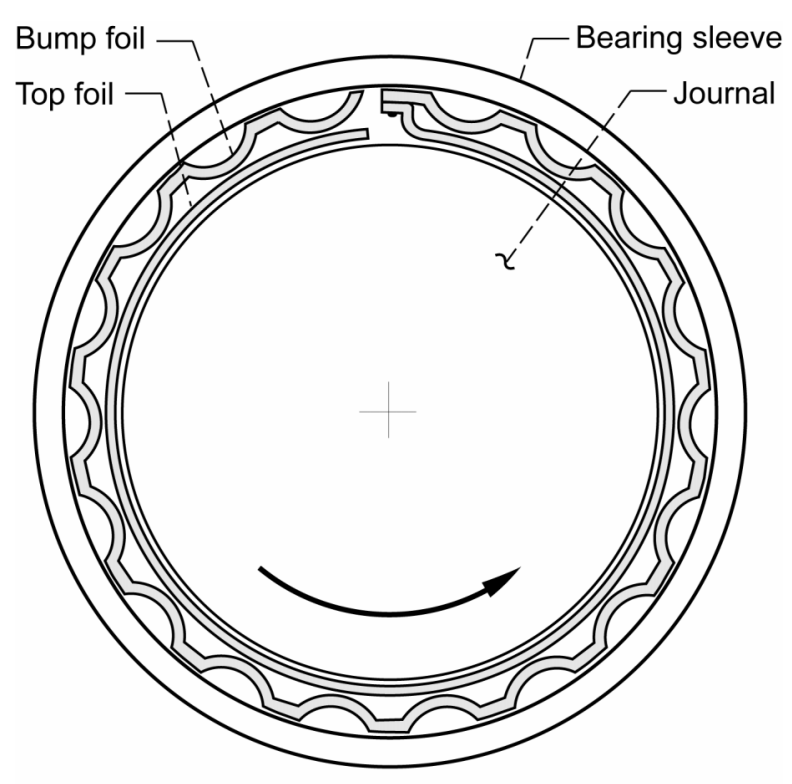

Figure 1.-Gas Foil Bearing Schematic.

up of a layer of corrugated sheet metal foil referred to as bump foils, whose bumps behave like springs (ref. 3). The bump foil layer gives the bearing flexibility that allows it to tolerate significant amounts of misalignment, and distortion that would otherwise cause a rigid bearing to fail. In addition, micro-sliding between the top foil and bump foil and the bump foil and the housing generates Coulomb damping which can increase the dynamic stability of the rotor-bearing system (ref. 4). Though not as common, other designs exist to achieve an elastic foundation for the compliant top foil, such as overlapping leaves, cantilevered springs, and others.

During normal operation of a foil bearing supported machine, the rotation of the rotor generates a pressurized gas film that "pushes" the top foil out radially and separates the top foil from the surface of the rotating shaft. The pressure in the gas film is proportional to the relative surface velocity between the rotor and the foil bearing top foil. Thus, the faster the rotor rotates, the higher the pressure, and the more load the bearing can support. When the rotor first begins to rotate, the top foil and the rotor surface are in contact until the speed increases to a point where the pressure in the gas film is sufficient to push the top foil away from the rotor, and support its weight. Likewise, when the rotor slows down to a point where the speed is insufficient to support the rotor weight, the top foil and rotor again come in contact.

Therefore, during start-up and shut down, a solid lubricant coating is used, either on the shaft surface or the foil, to reduce wear and friction (ref. 5).

The tolerance to misalignment mentioned above is as yet an unknown for GFBs. Manufacturers claim GFBs can handle large misalignment due to the flexible nature of the inner bearing surface, but there is little experimental or analytical verification of this capability. In an effort to address these concerns, the effects of misalignment are investigated experimentally in the current work.

\section{Misalignment}

An important issue for all turbomachinery, and therefore important for gas foil bearing systems is the degree of misalignment that a rotor bearing system can tolerate. The limits on misalignment dictate how precisely housings must be manufactured or whether bearings must be mounted in self- aligning fixtures, and how much thermal distortion can be tolerated. GFBs have been touted as having the ability to handle high degrees of misalignment relative to other bearing types, thus making them easier to integrate into 
high speed, high temperature applications. However, very little work has been reported on GFB misalignment. Carpino (ref. 6) computationally analyzed misalignment effects and found that minimum film thickness decreases with increased misalignment. Those results were for very small angular misalignments (maximum angle equal to the clearance/length radians) relative to those in the present tests (maximum angle approximately 10 times larger, assuming a clearance on the order of $25 \mu \mathrm{m}$ ), yet make clear a concern associated with misalignment. The viscous losses in the bearing, which lead to power loss and heat generation, are proportional to the viscosity of the gas, and the wall shear stress of the fluid film (which varies inversely with the gas film thickness). Therefore, smaller minimum film thickness, and therefore misalignment, leads to higher power loss and greater heat generation. Previously, Gray, et al. (ref. 7) reported misalignment capability of four different foil bearing configurations. They tested a "standard bearing", which is equivalent to what is referred to as a generation I foil bearing by Dellacorte and Valco (ref. 8), a two-layered bump bearing with a second layer of bumps at the edge, a three-bump strip bearing, which has three separate bump strips axially (likely a generation II bearing), and a "standard bearing" mounted in a diaphragm type flexible mounting. Their results indicate that for a load of $55.1 \mathrm{kN} / \mathrm{m}^{2}$, the misalignment tolerance for the generation I and the two-layered bearings is similar, approximately $1.0 \mathrm{E}-3$ radians. The three-bump strip bearing is roughly $2.6 \mathrm{E}-3$ radians, and the flexibly mounted generation I bearing is roughly 7.0E-3 radians. It is difficult to compare these results to the current results because the bearing sizes, speeds, and loads are different. However, that said, the magnitude of the misalignment tolerated is of the same order regardless of size, speed and load, and more importantly, are all at least an order of magnitude higher than angular contact ball bearings.

Since angular contact ball bearings are typically used in the class of machines for which GFBs are considered as replacements, it is appropriate to compare the misalignment tolerance of the two. The amount of misalignment ball bearings can tolerate depends on the size, load, speed, and required life, but according to Zaretsky (ref. 9), a typical allowable maximum angle of misalignment for angular contact ball bearings is $3 \mathrm{E}-4$ radians. The current test program was instigated to quantify the level of misalignment GFBs can tolerate for comparison and to help guide future oil-free turbomachinery engineering design programs.

\section{Experimental Setup}

The rotordynamic simulator test rig at NASA Glenn Research Center (fig. 2) (ref. 10) was used to conduct misalignment tests on two journal GFBs. The specific geometry of the individual bumps is proprietary and the reader is referred to the patent for more details on the design (ref. 3). However, the bearings are classified as generation III bearings as defined in (ref. 8) and the basic geometry used is listed in table 1.

TABLE 1.-GAS FOIL BEARING GEOMETRY

\begin{tabular}{|l|r|}
\hline Nominal shell outside diameter & $63.5 \mathrm{~mm}$ \\
\hline Nominal shell inside diameter & $52.6 \mathrm{~mm}$ \\
\hline Nominal shaft diameter & $50.8 \mathrm{~mm}$ \\
\hline Nominal length & $40.6 \mathrm{~mm}$ \\
\hline Number of circumferential bumps & 35 \\
\hline
\end{tabular}

The rotordynamic simulator rig is an air turbine driven test rig that features completely oil-free operation. There are two journal GFBs at opposite ends of the rotor with two disks (a turbine and thrust bearing runner) mounted between the two journal bearings. In the configuration shown, the rotor weighs approximately $31 \mathrm{~N}(7.0 \mathrm{lb})$ and is roughly symmetric such that each journal bearing supports half the rotor weight for a loading of $6.0 \mathrm{kN} / \mathrm{m}^{2}$. The journal bearings are housed in independent structures that can be moved relative to each other in transverse and angular directions. The independent bearing supports allow the operator to impose a known misalignment on the two journal bearings using a laser based alignment system. Each foil bearing is mounted in a ball bearing supported rotating bearing carriage, as illustrated in figure 2 . The alignment system, shown in figure 3, consists of two laser heads, 
each having a laser emitter and sensor. One head attaches to each rotating bearing carriage. The bearing carriages rotate through $180^{\circ}$, and at three distinct angular positions, the laser alignment heads take measurements: $\pm 90^{\circ}$ from top dead center, and top dead center. From these three measurements, the lateral and angular alignment of the central axis of the rotating bearing carriages is calculated. The measurement accuracy of the laser alignment system is \pm 1.0 percent.

For the initial series of tests described here, one bearing structure was held fixed while the other was sequentially moved a small amount laterally $(0.127 \pm 0.001 \mathrm{~mm}$ for each test $)$ imposing a misalignment to both bearings. Two physical quantities were measured during these tests, temperature and coastdowntime. The temperature was measured using type $\mathrm{T}$ thermocouples (open ball, 40 gauge, with a temperature range of $-100{ }^{\circ} \mathrm{C}$ to $400{ }^{\circ} \mathrm{C}, \pm 0.08$ percent accuracy) glued with thermally conductive epoxy to the underside of the bearing top foil close to the edge, $\pm 90^{\circ}$ from top dead center, and at both ends for a total of 8 thermocouples, 4 on each bearing (figs. 4 and 8). Each test was run until the temperatures at a given test condition stabilized, indicating steady state operation. Data was collected at 20,000 rpm, which is a convenient speed to run the test rig in terms of vibration, noise, and time to reach steady state. The expected result was to see overall higher temperatures and higher temperature gradients between opposite sides of the bearings (T2 vs. T1 for example) at higher misalignment levels. The other observed quantity, coast-down time, was used as an indirect measure of bearing torque. It was anticipated that as the level of misalignment increased, the coast-down time would decrease due to higher bearing losses.

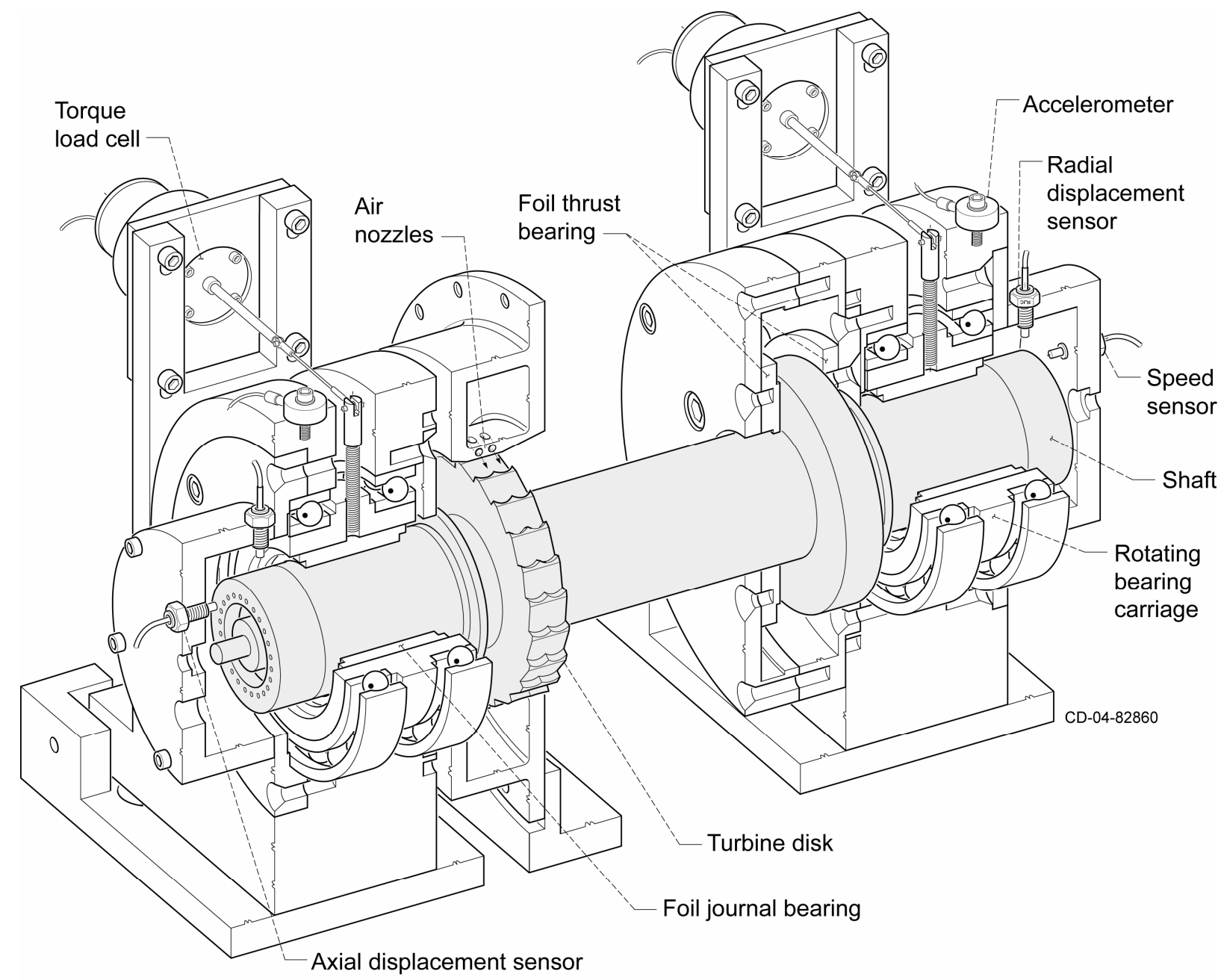

Figure 2.-Cutaway view of the rotordynamic simulator test rig. 


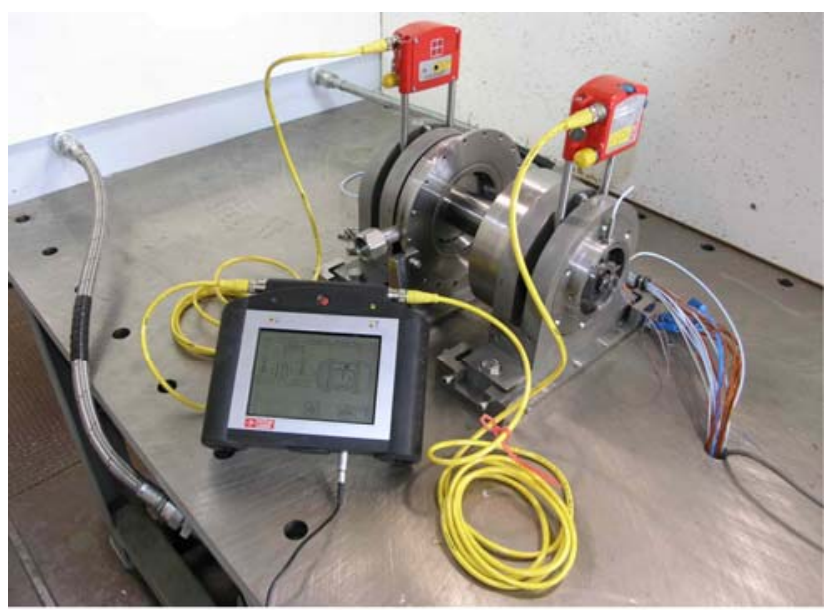

Figure 3.-Photograph of the test rig with the laser alignment system in place.

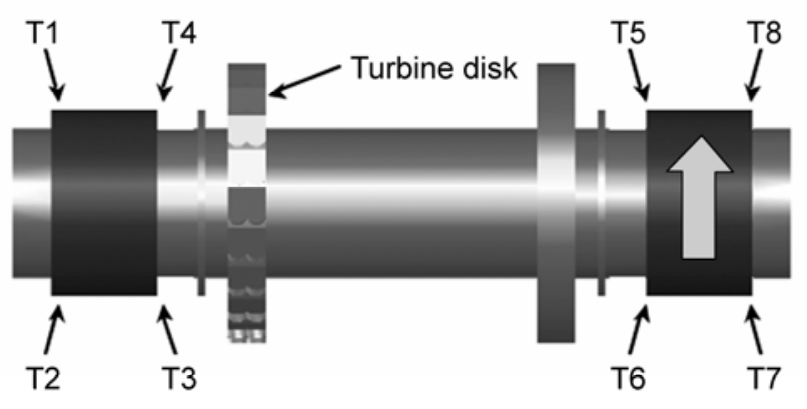

Figure 4.-Lateral misalignment method showing thermocouple locations looking down from the top. The left bearing is stationary. The right bearing moves laterally $0.127 \mathrm{~mm}$ for each incremental test.

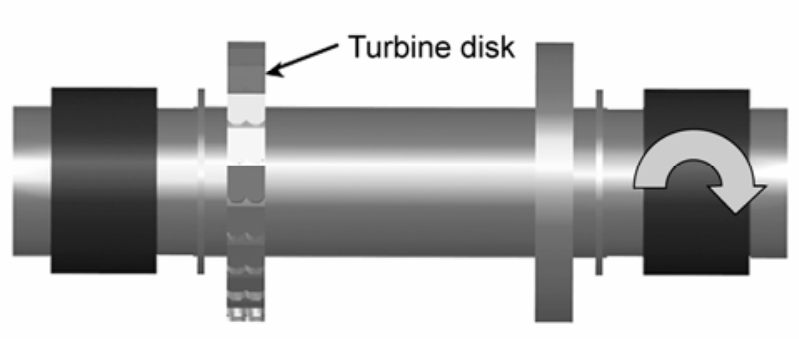

Figure 5.-Angular misalignment method. The left bearing is stationary. The right bearing moves angularly $5.0^{-4}$ radians for each incremental test.

In an effort to determine if the method of misalignment has a significant effect, additional tests were conducted using a different set of bearings without thermocouples. In these tests, two misalignment methods were used. The first method imposed a misalignment by holding both bearings fixed laterally, and rotating one bearing as illustrated in figure 5 . In the second misalignment method, the same technique was used as the previous bearings, a lateral misalignment like the previous tests illustrated in figure 4. A different set of bearings was used without thermocouples because the thermocouples were extremely fragile and easily damaged. Additionally, as discussed later, there was a concern that the thermocouples affected the behavior of the bearings, and therefore may have influenced the results to some extent. Since there were no thermocouples on the bearings, it was not possible to determine when steady state temperature operation was reached. Therefore, each test was run for $40 \mathrm{~min}$, which based upon the previous tests with thermocouples, is ample time to reach steady state operation. These tests were simply a go/no go type of test to determine a misalignment limit, and if there was a difference between the two misalignment methods.

In addition, during this second set of tests, the displacement of the rotor in the vertical and horizontal directions at each end of the rotor were measured using eddy current displacement sensors to see if misalignment has an observable effect on the dynamics of the system. 


\section{Misalignment Results and discussion}

\section{Temperature Results}

Figure 6 shows the temperature data for steady operation at 20,000 rpm. In general, there is an upward trend on temperature with higher misalignment, as anticipated. The exceptions to the trend are T3 and T4. One possible cause of the downward trend in T3 and T4 is their proximity to the turbine, seen in figure 4. Since T3 and T4 are adjacent to the turbine, they are affected by the temperature of the turbine outlet flow. The turbine is driven by compressed air, and as the air expands through the nozzle, it cools. At higher misalignment, more flow is required to counteract the higher torque, resulting in more turbine exhaust. The increased turbine exhaust may cool the bearing in the location where T3 and T4 are mounted.

When the GFBs are misaligned, the bearings become more and more edge-loaded. The thermocouples were placed on the bearing in such a way to try to see the effect of the edge-loading in the form of increased temperature. For example, as the right hand bearing in figure 4 is moved upward in the picture, the film thickness near thermocouples T2, T4, T6, and T8 decreases, while at T1, T3, T5, and T7 it increases. Because thinner films are associated with higher heat generation, T2 should be hotter than T1, T4 hotter than T3, T6 hotter than T5, and T8 hotter than T7. In general, this result is observed. It should be noted that thermocouple T6 was damaged while increasing the misalignment after the run at 3.7E-3 radians of misalignment, so there is no data for $\mathrm{T} 6$ beyond that test. Up to that point, it was behaving as expected.

At a maximum misalignment of 5.8E-3 radians $\pm 0.07 \mathrm{E}-3$ radians $(1.40 \mathrm{~mm} \pm 0.01 \mathrm{~mm}$ over a $241 \mathrm{~mm}$ $\pm 1 \mathrm{~mm}$ span) and 20,000 rpm, a failure was experienced and testing was stopped. GFBs can fail in several ways (refs. 11 and 12), but this failure was typical of the failure mode seen when load capacity is reached. The torque in the bearings increases rapidly, accompanied by an increase in temperature with no increase in speed or load. At the onset of the failure, it was observed that more turbine pressure was needed to maintain the same speed. As the failure progressed, more turbine pressure could not overcome the increase in torque, and speed decreased even with more pressure. When this occurred, the test was stopped.

In the second set of tests, it was not possible to reach failure due to misalignment with either the angular or the translational misalignment. Thus, it was not possible to determine if the misalignment method had any affect on the rotor/bearing system. The maximum amount of misalignment capable in the test rig, 8.0E-3 radians, is dictated by a clearance hole around the bolts that hold the bearing structures to the table. At 8.0E-3 radians, the clearance around the bolts was reached and the bolts were contacting the structure. For future testing, modifications will be considered to enable more misalignment. Still, the preliminary result obtained here of no failure up to at least $8.0 \mathrm{E}-3$ radians is a notable finding in that it is a very large amount of misalignment in terms of actual hardware. This is equivalent to $8 \mu \mathrm{m} / \mathrm{mm}$ of misalignment. 


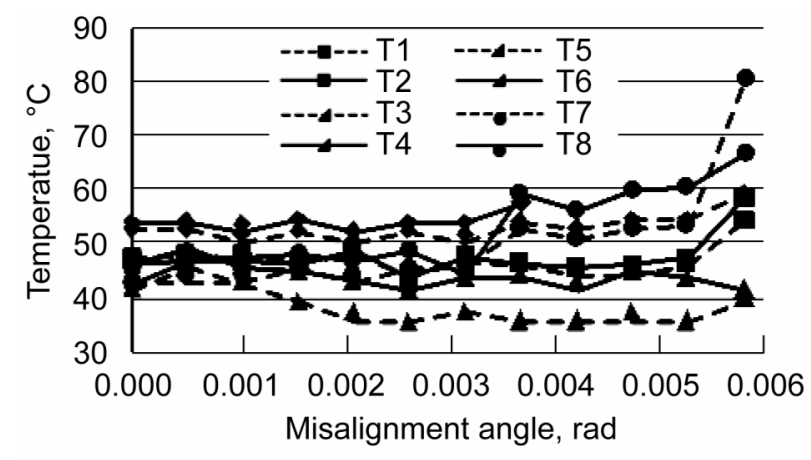

Figure 6.-Foil bearing edge temperatures at $20,000 \mathrm{rpm}$.
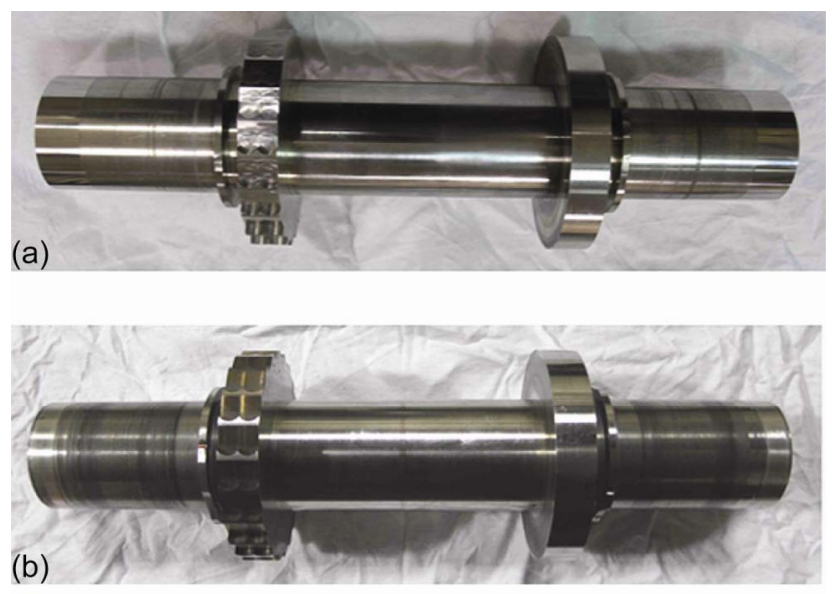

Figure 7.-Photographs of the rotor before and after misalignment tests showing edge wear in the shaft coating in photo (b). (a) Rotor before misalignment tests.

(b) Rotor after misalignment tests.

Standard precision machining and/or high thermal distortion should not cause this much misalignment. For example, in the test rig with a $241 \mathrm{~mm}$ bearing span, in order to induce misalignment that severe, the bearings had to be laterally misalignment by $1.93 \mathrm{~mm}$. This result indicates that gas foil bearings can tolerate extreme misalignment without catastrophic failure. Additionally, there are other reasons to avoid high levels of misalignment that make it unnecessary to test further. While the bearings did not fail, the coast-down time decreases with more misalignment as seen later in figures 9 and 10, indicating torque levels are increasing. Thus, power loss will increase with misalignment causing an efficiency penalty, increased thermal management requirements, and large start-up power demands. Increased wear of surface coatings with misalignment is also a concern. Figures 7(a) and (b) show the test rig rotor before testing began and after final disassembly, respectively. Figure 8 shows two of the test bearings after misalignment testing. The wear at the edges of the bearing locations on the rotor and at the edges of the bearings is evident. Additionally, other components in the turbomachine cannot tolerate such extreme misalignment levels. The tip clearances in the compressor and turbine of such machines would need to increase, resulting in efficiency losses.

The results of this second set of tests gives an indication of another reason for not instrumenting the second set of bearings with thermocoples. The bearings with thermocouples failed at a misalignment of $5.8 \mathrm{E}-3$ radians, while the un-instrumented bearings did not fail at $8.0 \mathrm{E}-3$ radians. The reason for this is believed to be the relative tightness of the bearings. The bearings with the thermocouples were noticeably tighter than the bearings without thermocouples. In addition to manufacturing variability between the 
different bearings, the process of installing the thermocouples could have caused a decrease in the clearance of the bearings. Previous work has shown that decreased clearance can have the effect of decreasing a bearing's load capacity (ref. 12). In a similar manner, a decrease in clearance, or an increase in tightness, apparently can decrease misalignment tolerance as well. This observation along with the observation that the failure mode was identical to a load capacity failure, leads one to believe that load capacity and misalignment may combine in an additive fashion to contribute to bearing failure. In other words, it is probable that a perfectly aligned bearing has a certain load capacity at a given speed. Any misalignment would result in a decrease in load capacity. Similarly, a given bearing can tolerate less misalignment the more heavily it is loaded relative to its load capacity. More work is needed to determine this relationship, but it is believed to be the cause of one bearing set failing and the other not failing. In any case, the second set of bearings was not instrumented to eliminate the possibility of affecting the results.
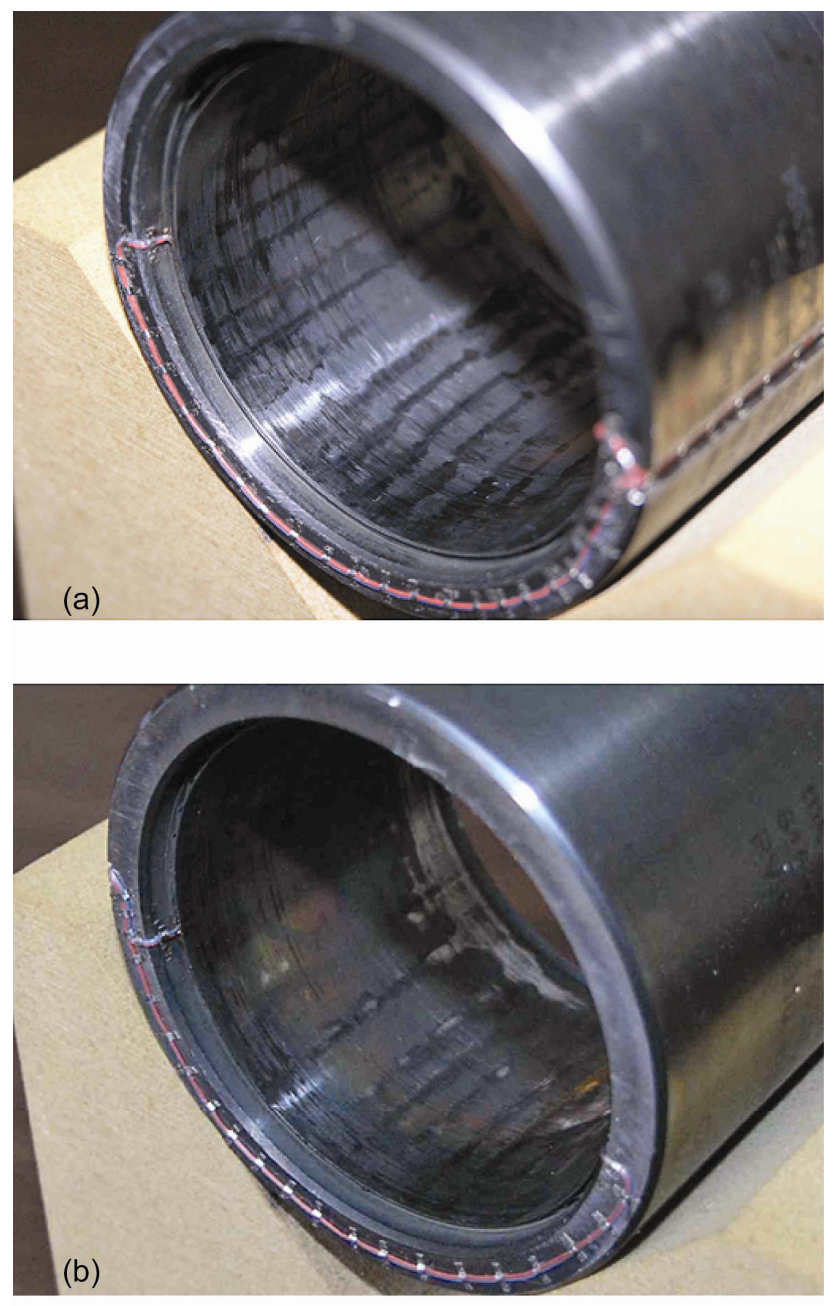

Figure 8.- Sample photographs of the test bearings after misalignment tests showing top foil wear patterns and thermocouple placement. (a) Turbine end bearing.

(b) Compressor end bearing.

\section{Coast-Down Results}


Figure 9 shows the coast-down time data as a function of misalignment, for both the lateral and the angular misalignment tests. The time represents how long it took to coast to a stop from a speed of $25,000 \mathrm{rpm}$. The trend shows that there is a general decrease in the time it takes to coast to a stop from a fixed speed as the misalignment increases. The decrease in coast-down time can be attributed to increased power loss, or torque in the bearings. It was not known a priori how severe the wear would be at the edge of the bearings and in the shaft coating for each shut-down event. Therefore, in an effort to minimize the amount of wear to the rotor/bearing system, the coast-down test was conducted once for each misalignment condition. While the repeatability is unknown, the results do show a reasonable trend. Since the coast-down tests were only intended to verify the assertion that torque increases with misalignment, this was deemed an acceptable compromise.

Modifications are planned for the rig to enable direct torque measurements in the future. Still, quite a bit of insight can be gained by looking at the coast-down data. Figure 10 shows the same coast-down test results plotted a different way. Here, the speed versus time is shown over the entire coast-down event. In figures 10(a) and (b), three misalignment conditions are shown: small, intermediate, and large

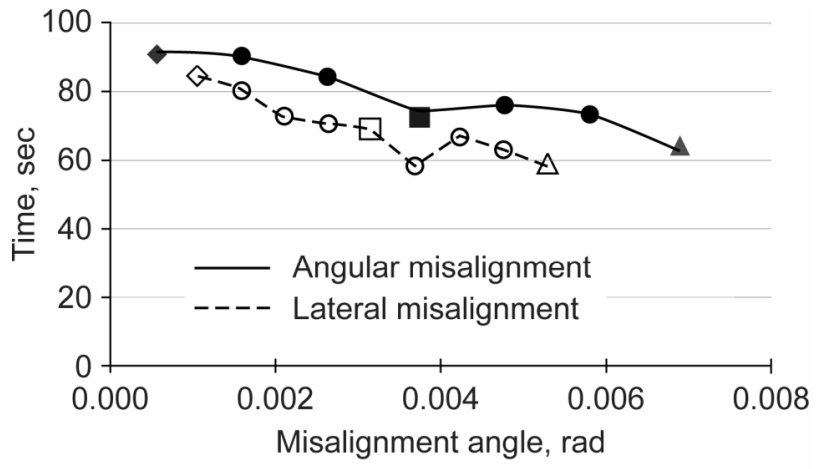

Figure 9.-Coast-down time as a function of misalignment. 

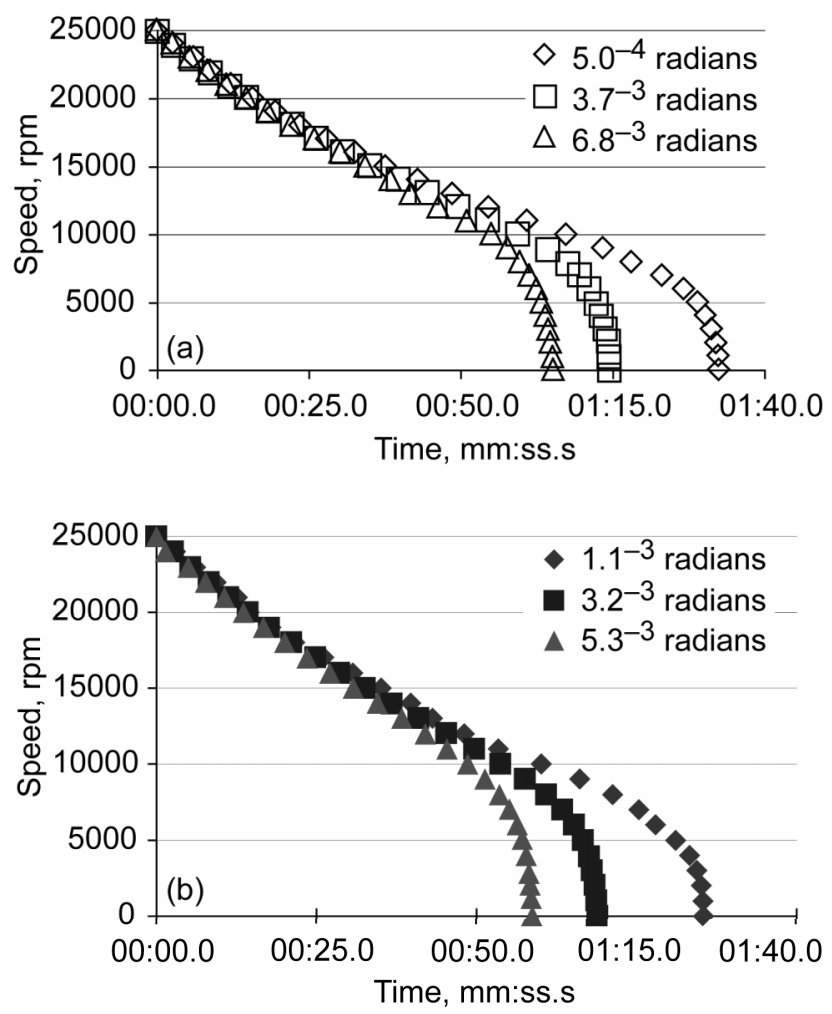

Figure 10.-Plots of the evolution of speed during coast-down for three lateral and angular misalignment conditions. (a) Speed versus time for coast-down at three lateral misalignment levels. (b) Speed versus time for coast-down at three angular misalignment levels.

misalignment cases in each figure. Figure 10(a) is from the lateral misalignment test, and figure 10(b) from the angular misalignment test. The shape of the data points corresponds with the shape of the data points in figure 9 for cross-reference. The slope of these plots is the angular acceleration of the test rotor. One can see that the rotor decelerates at about the same rate initially for all the cases, but slows down quicker for the misaligned cases near the end of the coast-down event. One can also see the effect of misalignment on what is termed the lift-off speed (or touch-down speed in the case of a coast-down) of the foil bearings. The lift-off speed is the speed at which a gas film has fully developed and the rotor weight is supported on the gas film. It makes sense in the context of coast-down testing to think in terms of touch-down speed, but they are essentially interchangeable for the purpose of this discussion. Below the touch-down speed, there is still metal-to-metal contact, and therefore, the torque is higher. Therefore, at the touch-down speed one would expect to see a significant change in the deceleration of the rotor due to a sudden increase in torque. This can, in fact, be seen in figures 10(a) and (b), and manifests itself as the knee in the curves. Additionally, as the misalignment increases in both plots, the touch-down speed increases. Thus, increased misalignment causes an increase in touch-down, or lift-off speed in much the same manner as increased load would cause an increase in lift-off speed.

\section{Rotordynamic Results}


The final observation of this series of testing is the rotordynamic behavior of the system as it changes with increased misalignment. The observations are preliminary, but are noteworthy and deserving of further investigation. As the angle of misalignment increases, the results are consistent with a stiffening of the bearing. This result is not altogether surprising, and complements the results of Carpino (ref. 6) mentioned earlier. Since increased misalignment leads to smaller minimum film thicknesses, which result in higher gas film pressures, it stands to reason that increased misalignment would lead to increased stiffness. The indication of this can be seen in figure 11 with three plots of the vertical vibration at the misaligned bearing end of the rotor as a sample. The figure shows synchronous vibration (Bode) plots of low, medium, and high misalignment from the top down; 5.0E-4, 3.7E-3, and 6.8E-3 radians respectively. One can see what looks like two potential critical speeds in the top plot at 4,500 and 12,500 rpm. In the middle and bottom plots these peaks move up to approximately 5,600 and 13,500 rpm, and 9,000 and $15,000 \mathrm{rpm}$ respectively. This increase in frequencies indicates the possible stiffening of the bearing one might expect. In addition, the shape, specifically the width of the peaks, changes as the misalignment increases indicating a possible change to the damping coefficients as well. Further testing is needed to verify that these peaks are critical speeds, and corresponding mode shapes of the rotor/bearing system. If they are critical speeds, the increase in frequency and width are consistent with an increase in bearing stiffness and damping.

Another rotordynamics observation relates to subsynchronous vibrations. Figure 12 shows three waterfall plots of the same vibration variable as figure 11 for coast-down events at the same three levels of misalignment. At the lowest misalignment, the top plot, there are subsynchronous components in the vibration that begin to show up at around 17,000 rpm. As the misalignment increases in the middle plot to 3.7E-3 radians, the speed at which the subsynchronous vibrations begin to appear increases to around $22,000 \mathrm{rpm}$. At the highest misalignment, 6.8E-3 radians, there are essentially no subsynchronous vibrations up to the maximum speed of $25,000 \mathrm{rpm}$. While more analysis is needed to determine the source of the subsynchronous vibrations, it is interesting to note that they occur near the frequencies of the vibratory peaks observed in figure 11. San Andres, et al. (ref. 13) have reported similar subsynchronous vibrations with the exception that they found the subsynchronous frequency to track the run speed at a ratio of 50 percent, where here, the frequencies seem to be fairly constant and possibly locked into the rigid body critical speeds of the rotor. This result, an increase in the speed at which subsynchronous vibrations appear, is consistent with the observed widening of peaks above as an increase in bearing damping. Again, additional testing and future analysis is needed to fully understand this outcome, but it is clear that misalignment can have an effect on system rotordynamics. 

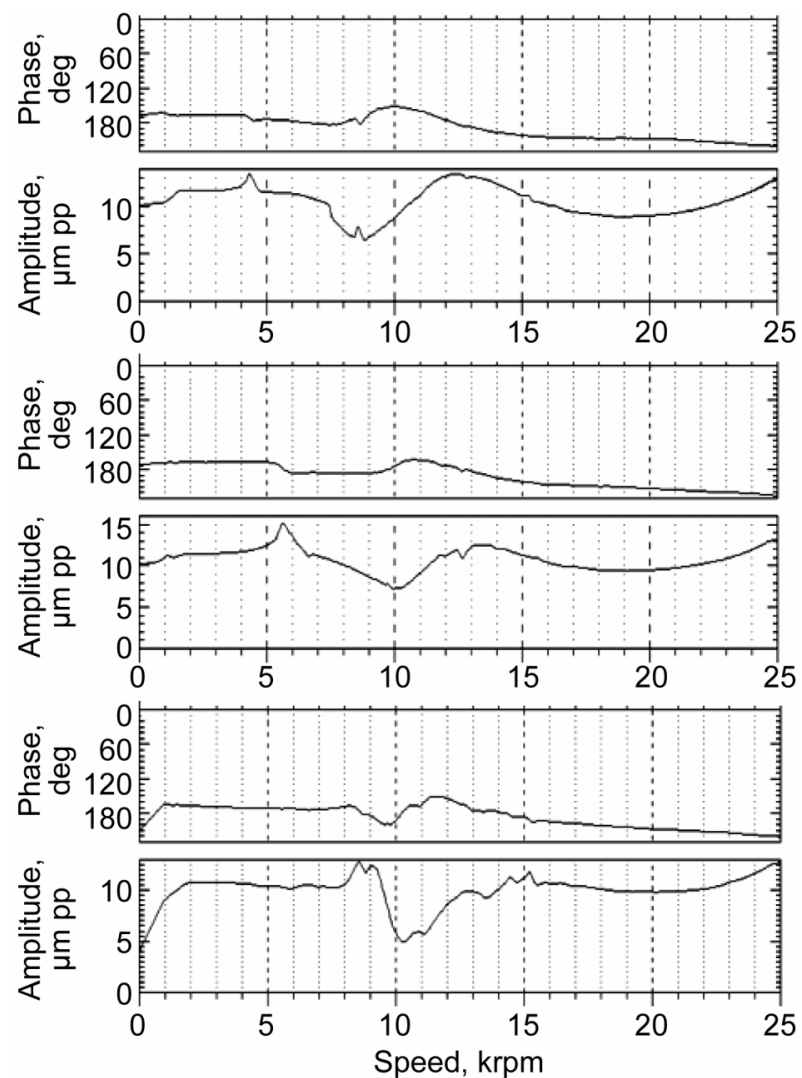

Figure 11.-Plots of the synchronous vertical vibration amplitude (Bode plot) at the angular misaligned bearing end of the rotor. The misalignments are $5.0^{-4}, 3.7^{-3}$, and $6.8^{-3}$ radians respectively from the top down.
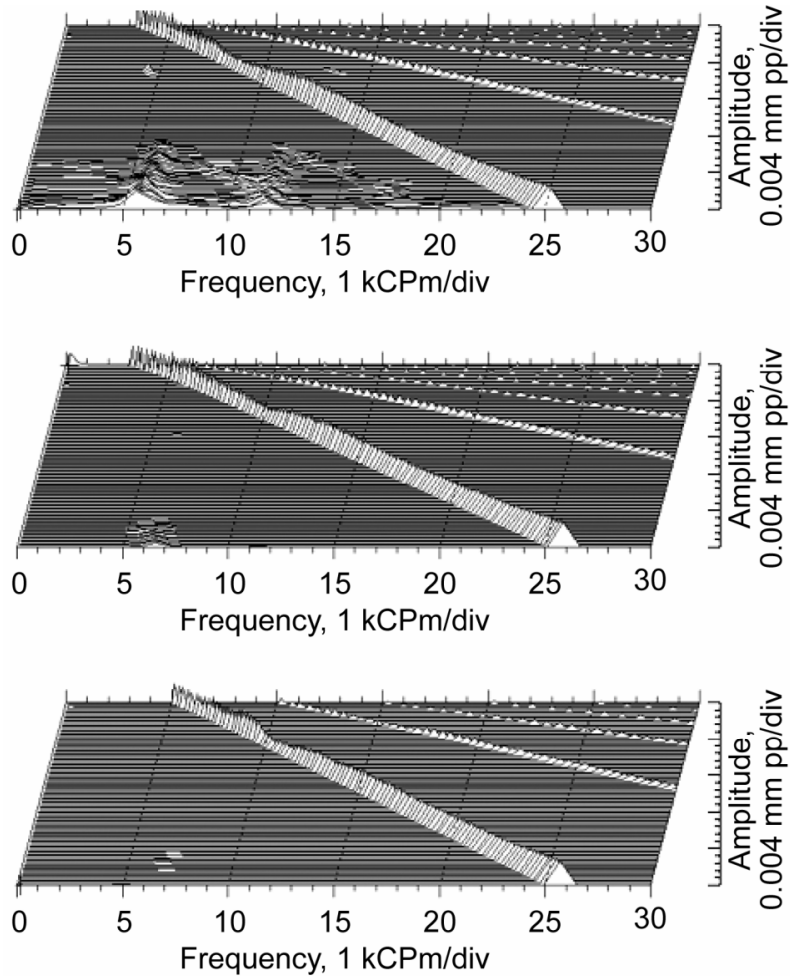

Figure 12.-Waterfall plots for increasing levels of misalignment, $1.0^{-3}, 3.7^{-3}$, and $6.8^{-3}$ radians respectively from the top down.

\section{Conclusions}

Future widespread use of gas foil bearings in high performance turbomachinery will demand an understanding of the importance of and engineering design guidelines for important system level considerations such as thermal management schemes, alignment precision, balance requirements, thrust load balancing, etc. The present experimental results indicate that gas foil bearings are quite tolerant of high levels of misalignment, at least an order of magnitude higher than angular contact ball bearings, the technology they most often replace. However, because of other system requirements such as a desire to keep bearing power loss and wear low, and compressor and turbine tip clearance requirements, allowable misalignment limits for a given machine are likely to be much lower than what the GFB could handle. The implication of this, from an engineering perspective, is that present design practices regarding machine precision and stack-up tolerances should be sufficient for integrating GFBs into future high performance turbomachinery. The necessity of special design practices, such as flexible, self-aligning bearing mounts, are not likely to be required. In addition, while the full implications are yet to be discovered, GFB misalignment appears to have an influence on system rotordynamics in terms of bearing force coefficients and the onset of subsynchronous vibrations. 


\section{References}

1. Heshmat, H., Walton, J.F., DellaCorte, C., and Valco, M.J., 2000, "Oil-Free Turbocharger Demonstration Paves the Way to Gas Turbine Engine Applications," ASME Paper No. 2000-GT-620.

2. Mason, L.S., 2003, “A Power Conversion Concept for the Jupiter Icy Moons Orbiter," AIAA-20036007.

3. Heshmat, H., 2000, "High Load Capacity Compliant Foil Hydrodynamic Journal Bearing," U.S. Patent 6,158,893.

4. Heshmat, H., 1994, "Advancements in the Performance of Aerodynamic Foil Journal Bearings: High Speed and Load Capability,” ASME J. Tribol., 116, pp. 287-295.

5. DellaCorte, C., 1998, "The Evaluation of a Modified Chrome Oxide Based High Temperature Solid Lubricant Coating for Foil Gas Bearings," NASA/TM-1998-208660, National Aeronautics and Space Administration, Cleveland, $\mathrm{OH}$.

6. Carpino, M., Peng, J.P., and Medvetz, L., 1994, "Misalignment in a Complete Shell Gas Foil Journal Bearing," Tribology Transactions, 37(4), pp. 829-835.

7. Gray, S., Heshmat, H., and Bhushan, B., 1981, "Technology Progress on Compliant Foil Air Bearing Systems for Commercial Applications," Paper No. 6, Proc. of the $8^{\text {th }}$ International Gas Bearing Symposium, BHRA Fluid Engineering, Cranfield, Bedford, England, pp. 70-97.

8. Dellacorte, C., and Valco, M.J., 2000, "Load Capacity Estimation of Foil Air Journal Bearings for Oil-Free Turbomachinery Applications," NASA/TM-2000-209782, National Aeronautics and Space Administration, Cleveland, $\mathrm{OH}$.

9. Zaretsky, E.V., 1992, Life Factors for Rolling Bearings, Society of Tribologists and Lubrication Engineers, Park Ridge, IL, pp. 145-158, Chap. 4.

10. Howard, S.A., 2007, "A New High-Speed Oil-Free Turbine Engine Rotordynamic Simulator Test Rig," NASA/TM-2007-214489, National Aeronautics and Space Administration, Cleveland, OH.

11. Dykas, B.D., and Howard, S.A., 2004, "Journal Design Considerations for Turbomachine Shafts Supported on Foil Air Bearings," Tribology Transactions, 47(4), pp. 508-516.

12. Radil, K.C., Howard, S.A., and Dykas, B.D., 2002, "The Role of Radial Clearance on the Performance of Foil Air Bearings," NASA/TM-2002-211705, National Aeronautics and Space Administration, Cleveland, $\mathrm{OH}$.

13. SanAndres, L., Rubio, D., and Kim, T.H., 2007, "Rotordynamic Performance of a Rotor Supported on Bump Type Foil Gas Bearings: Experiments and Predictions," ASME J. of Engineering for Gas Turbines and Power, 129(3), pp. 850-857. 


\begin{tabular}{|c|c|c|c|c|c|}
\hline \multicolumn{5}{|c|}{ REPORT DOCUMENTATION PAGE } & $\begin{array}{l}\text { Form Approved } \\
\text { OMB No. 0704-0188 }\end{array}$ \\
\hline \multicolumn{6}{|c|}{$\begin{array}{l}\text { The public reporting burden for this collection of information is estimated to average } 1 \text { hour per response, including the time for reviewing instructions, searching existing data sources, gathering and maintaining the } \\
\text { data needed, and completing and reviewing the collection of information. Send comments regarding this burden estimate or any other aspect of this collection of information, including suggestions for reducing this } \\
\text { burden, to Department of Defense, Washington Headquarters Services, Directorate for Information Operations and Reports (0704-0188, } 1215 \text { Jefferson Davis Highway, Suite } 1204 \text {, Arlington, VA } 22202-4302 \text {. } \\
\text { Respondents should be aware that notwithstanding any other provision of law, no person shall be subject to any penalty for failing to comply with a collection of information if it does not display a currently valid OMB } \\
\text { control number. } \\
\text { PLEASE DO NOT RETURN YOUR FORM TO THE ABOVE ADDRESS. }\end{array}$} \\
\hline \multicolumn{2}{|c|}{$\begin{array}{l}\text { 1. REPORT DATE (DD-MM-YYYY) } \\
01-05-2008\end{array}$} & \multicolumn{3}{|c|}{$\begin{array}{l}\text { 2. REPORT TYPE } \\
\text { Technical Memorandum }\end{array}$} & 3. DATES COVERED (From - To) \\
\hline \multirow{3}{*}{\multicolumn{5}{|c|}{$\begin{array}{l}\text { 4. TITLE AND SUBTITLE } \\
\text { Misalignment in Gas Foil Journal Bearings: An Experimental Study }\end{array}$}} & 5a. CONTRACT NUMBER \\
\hline & & & & & 5b. GRANT NUMBER \\
\hline & & & & & 5c. PROGRAM ELEMENT NUMBER \\
\hline \multirow{3}{*}{\multicolumn{4}{|c|}{$\begin{array}{l}\text { 6. AUTHOR(S) } \\
\text { Howard, Samuel, A. }\end{array}$}} & & 5d. PROJECT NUMBER \\
\hline & & & & & 5e. TASK NUMBER \\
\hline & & & & & $\begin{array}{l}\text { 5f. WORK UNIT NUMBER } \\
\text { WBS 877686.02.07.03.01.01 }\end{array}$ \\
\hline \multicolumn{5}{|c|}{$\begin{array}{l}\text { 7. PERFORMING ORGANIZATION NAME(S) AND ADDRESS(ES) } \\
\text { National Aeronautics and Space Administration } \\
\text { John H. Glenn Research Center at Lewis Field } \\
\text { Cleveland, Ohio 44135-3191 }\end{array}$} & $\begin{array}{l}\text { 8. PERFORMING ORGANIZATION } \\
\text { REPORT NUMBER } \\
\text { E-16489-1 }\end{array}$ \\
\hline \multirow{2}{*}{\multicolumn{5}{|c|}{$\begin{array}{l}\text { 9. SPONSORING/MONITORING AGENCY NAME(S) AND ADDRESS(ES) } \\
\text { National Aeronautics and Space Administration } \\
\text { Washington, DC 20546-0001 }\end{array}$}} & $\begin{array}{l}\text { 10. SPONSORING/MONITORS } \\
\text { ACRONYM(S) } \\
\text { NASA }\end{array}$ \\
\hline & & & & & $\begin{array}{l}\text { 11. SPONSORING/MONITORING } \\
\text { REPORT NUMBER } \\
\text { NASA/TM-2008-215223 }\end{array}$ \\
\hline \multicolumn{6}{|c|}{$\begin{array}{l}\text { 12. DISTRIBUTION/AVAILABILITY STATEMENT } \\
\text { Unclassified-Unlimited } \\
\text { Subject Category: } 37 \\
\text { Available electronically at http://gltrs.grc.nasa.gov } \\
\text { This publication is available from the NASA Center for AeroSpace Information, 301-621-0390 }\end{array}$} \\
\hline \multicolumn{6}{|c|}{ 13. SUPPLEMENTARY NOTES } \\
\hline \multicolumn{6}{|c|}{$\begin{array}{l}\text { 14. ABSTRACT } \\
\text { As gas foil journal bearings become more prevalent in production machines, such as small gas turbine propulsion systems and } \\
\text { microturbines, system-level performance issues must be identified and quantified in order to provide for successful design practices. Several } \\
\text { examples of system-level design parameters that are not fully understood in foil bearing systems are thermal management schemes, } \\
\text { alignment requirements, balance requirements, thrust load balancing, and others. In order to address some of these deficiencies and begin to } \\
\text { develop guidelines, this paper presents a preliminary experimental investigation of the misalignment tolerance of gas foil journal bearing } \\
\text { systems. Using a notional gas foil bearing supported rotor and a laser-based shaft alignment system, increasing levels of misalignment are } \\
\text { imparted to the bearing supports while monitoring temperature at the bearing edges. The amount of misalignment that induces bearing } \\
\text { failure is identified and compared to other conventional bearing types such as cylindrical roller bearings and angular contact ball bearings. } \\
\text { Additionally, the dynamic response of the rotor indicates that the gas foil bearing force coefficients may be affected by misalignment. }\end{array}$} \\
\hline \multicolumn{6}{|c|}{$\begin{array}{l}\text { 15. SUBJECT TERMS } \\
\text { Gas bearings; Foil bearings; Turbomachinery; Rotordynamics; Bearings }\end{array}$} \\
\hline \multicolumn{3}{|c|}{ 16. SECURITY CLASSIFICATION OF: } & $\begin{array}{l}\text { 17. LIMITATION OF } \\
\text { ABSTRACT }\end{array}$ & $\begin{array}{l}\text { 18. NUMBER } \\
\text { OF }\end{array}$ & $\begin{array}{l}\text { 19a. NAME OF RESPONSIBLE PERSON } \\
\text { STI Help Desk (email:help } a \text { sti.nasa.gov) }\end{array}$ \\
\hline $\begin{array}{l}\text { a. REPORT } \\
\text { U }\end{array}$ & $\begin{array}{l}\text { b. ABSTRACT } \\
\text { U }\end{array}$ & $\begin{array}{l}\text { c. THIS } \\
\text { PAGE } \\
\text { U }\end{array}$ & UU & $\begin{array}{l}\text { PAGES } \\
19\end{array}$ & $\begin{array}{l}\text { 19b. TELEPHONE NUMBER (include area code) } \\
\text { 301-621-0390 }\end{array}$ \\
\hline
\end{tabular}



